\title{
PERTUMBUHAN PADI GOGO DI MEDIUM ULTISOL DENGAN PEMBERIAN CAMPURAN FOSFAT ALAM DAN COCOPEAT PADA DUA KONDISI KADAR AIR
}

\author{
Pedri Antoro ${ }^{1}$ dan Nelvia Nelvia ${ }^{1}$ \\ ${ }^{1}$ Jurusan Agroteknologi Fakultas Pertanian Universitas Riau \\ Kampus Bina Widya Universitas Riau, Jl. HR. Soebrantas KM 12,5 Pekanbaru, Indonesia 28293 \\ Email :nelvia@unri.ac.id; Mobile :+6281371248740
}

\begin{abstract}
The main problem of upland rice cultivation in Ultisol are fixation of $\mathrm{P}$, solubility and saturation of $\mathrm{Al}$ are the height and water content is low. The research aim to study the effect of interaction of application of mixture of cocopeat with rock phosphate (RP) on growth of upland rice in Ultisols medium at two water content condition. The research was conducted at the Green House of the Faculty of Agriculture, University of Riau, Pekanbaru from February to July 2017. This research in form factorial experiment was arranged in a completely randomized design. The first factor was mixture of RP with cocopeat consist of 7 levels $\left(0,30,45\right.$ and $60 \mathrm{~kg} \mathrm{P}_{2} \mathrm{O}_{5} /$ ha each dose + cocopeat dose 10 tons/ha and 30,45 and $60 \mathrm{~kg} \mathrm{P}_{2} \mathrm{O}_{5} /$ ha without cocopeat). The second factor was water content consists of 2 levels (field capacity and 25\% under field capacity), each combination repeated 3 times. The results show the application of rock phosphate dose of $30 \mathrm{~kg} \mathrm{P}_{2} \mathrm{O}_{5} / \mathrm{ha}+10$ tons cocopeat/ha or without cocopeat increased the growth of upland rice include plant high, number of maximum tiller and productive tiller and dry weight of straw compared to without RP both on the field capacity and $25 \%$ below field capacity condition, the increasing of RP dose to 45 $60 \mathrm{~kg} \mathrm{P}_{2} \mathrm{O}_{5} / \mathrm{ha}$ tended to increase each parameter.
\end{abstract}

Key words : rock phosphate, water content, cocopeat, upland rice.

(C) 2018 Pedri Antoro, Nelvia Nelvia

\section{PENDAHULUAN}

Beras sebagai makanan pokok di Indonesia kebutuhannya dari tahun ke tahun semakin meningkat seiring dengan pertambahan jumlah penduduk. Sebaliknya produksinya terus menurun karena alih fungsi lahan sawah subur menjadi non sawah dan penurunan peningkatan hasil (levling off) akibat pemupukan tidak berimbang. Perluasan areal tanaman padi salah satu cara meningkatkan produksi beras terutama padi gogo pada lahan kering. Ultisol adalah lahan kering yang cukup luas di Indonesia yaitu 45,8 juta ha atau $25 \%$ dari total daratan Indonesia (Prasetyo dan Suriadikarta, 2006), sehingga potensi besar untuk budidaya padi gogo.

Budidaya padi gogo pada Ultisol akan ditemui kendala kimia dan fisika. Kendala kimia diantaranya reaksi tanah masam, KTK, $\mathrm{KB}$, kandungan unsur hara seperti $\mathrm{N}, \mathrm{P}, \mathrm{K}, \mathrm{Ca}$,
Mg dan Mo rendah serta Al-dd dan kejenuhan Al tinggi (Subagyo et al., 2004). Hal yang sama di laporkan Zulputra et al (2014) bahwa Ultisol Pematang Berangan, Rambah, Rokan Hulu Riau bereaksi masam, Ca-dd, Mg-dd dan KTK rendah, C-organik, N-total, P-tersedia dan $\mathrm{K}$-dd sedang dan kejenuhan $\mathrm{Al}$ tergolong sangat tinggi (65\%). Kejenuhan $\mathrm{Al}$ dan $\mathrm{Al}-\mathrm{dd}$ tinggi menyebabkan tanaman keracunan dan fiksasi $\mathrm{P}$ tinggi. Kendala fisika terutama kemantapan agregat dan kemampuan tanah menahan air sangat rendah (Sinukaban dan Barus, 1984).

Fiksasi P yang tinggi pada ultisol dapat diatasi dengan menggunakan pupuk $\mathrm{P}$ lambat larut (slow release) seperti fosfat alam. Zulputra et al. (2014) melaporkan bahwa pemberian $\mathrm{P}$ (pupuk SP-36) dosis $36 \mathrm{~kg} \mathrm{P}_{2} \mathrm{O}_{5}$ dan silikat dosis $50 \mathrm{~kg} \mathrm{SiO} / 2 \mathrm{~kg}$ meningkatkan tinggi, jumlah anakan per rumpun dan bobot gabah padi gogo per $\mathrm{m}^{2}$ dibandingkan kontrol 
(tanpa P dan silikat). Agustin (2010) melaporkan bahwa cocopeat mempunyai berat jenis $0,75 \mathrm{~g} / \mathrm{cm}^{3}$, berat volume $0,13 \mathrm{~g} / \mathrm{cm}^{3}$ dan porositas 91,9\%. Menurut Ghehsareh et al., (2011) kharakteristik cocopeat sebagai berikut: nisbah $\mathrm{C} / \mathrm{N} 48, \quad$ BD 0,16 g/cm, pH 6,7, KTK $138,7 \mathrm{Cmol}^{(+)} / \mathrm{kg}$ ), N-total $1,98 \mathrm{mg} / \mathrm{L}$, P Olsen $1,32 \mathrm{mg} / \mathrm{L}$ dan $\mathrm{K}$ olsen $477,7 \mathrm{mg} / \mathrm{L}$.serta porositas $58 \%$ dan water holding capasity (WHC) 90,5\%. Hasriani et al. (2013) melaporkan kandungan air dan daya simpan air pada cocopeat tinggi masing-masing $119 \%$ dan $695,4 \%$.

.Oleh sebab itu pemberian cocopeat berperan meningkatkan kemampuan tanah menyerap dan menahan air.

Penelitian bertujuan mempelajari pengaruh interaksi antara campuran cocopeat dengan fosfat alam dan kadar air terhadap pertumbuhan tanaman padi gogo pada medium ultisol.

\section{BAHAN DAN METODA}

Penelitian dilakukan di Rumah Kaca dan Laboratorium Ilmu Tanah Fakultas Pertanian Universitas Riau dari bulan Februari hingga Juli 2017.

Bahan yang digunakan meliputi bahan tanah Ultisol berasaldari Desa Batu Belah, Kampar Riau, benih padi gogo varietas Situ Bagendit, FA dengan kadar $28 \% \mathrm{P}_{2} \mathrm{O}_{5}$ sebagai sumber $\mathrm{P}$, pupuk dasar (Urea dan $\mathrm{KCl}$ ) dan pestisida Curacron. Alat yang digunakan $\mathrm{pH}$ meter, AAS, spectrophotometer dll.

Penelitian berupa eksperimen dalam bentuk faktorial menggunakan Rancangan Acak Lengkap (RAL). Faktor pertama adalah campuran fosfat alam (FA) dengan cocopeat terdiri dari 7 taraf $\left(0,30,45\right.$ dan $60 \mathrm{~kg} \mathrm{P}_{2} \mathrm{O}_{5} / \mathrm{ha}$ masing-dicampur cocopeat dosis 10 ton /ha dan 30,45 dan $60 \quad \mathrm{~kg} \quad \mathrm{P}_{2} \mathrm{O}_{5} / \mathrm{ha}$ tanpa cocopeat).Faktor kedua adalah kadar air terdiri dari 2 taraf (kapasitas lapang /KL dan 25\% dibawah KL), masing-masing kombinasi diulang 3 kali.

Data hasil pengamatan dianalisis secara statistik menggunakan analisis ragam, kemudian dilanjutkan dengan uji Duncan's Multiple Range Test (DMRT) pada taraf 5\%.
Parameter yang diamati meliputi tinggi tanaman, jumlah anakan maksimum, jumlah anakan produktif dan bobot kering jerami.

\section{HASIL DAN PEMBAHASAN}

Ultisol yang digunakan untuk penelitian mempunyai kesuburan rendah. Hasil analisis sifat kimianya berdasarkan Kriteria menurut Pusat Penelitian Tanah dalam Hardjowigeno (2007) bereaksi masam (pH $\mathrm{H}_{2} \mathrm{O}$ 1:1 nilai 4,8 dan $\mathrm{pH} \mathrm{KCl}$ nilai 4,6), kadar $\mathrm{C}$ organik, $\mathrm{N}$ total, KTK, dan $\mathrm{KB}$ tergolong rendah berturut-turut $1,4 \%, \quad 0,2 \%, \quad 14$ $\mathrm{cmol}^{(+)} / / \mathrm{kg}$ dan $14,5 \%$, P tersedia rendah $(13,5$ $\mathrm{mg} / \mathrm{kg}$, dimana K-dd, Mg-dd dan Na-dd berturut-turut 0,$2 ; 0,5$ dan $0,4 \quad \mathrm{cmol}^{(+)} / \mathrm{kg}$ masing-masing tergolong rendah dan Ca-dd 1,0 $\mathrm{Cmol} / \mathrm{kg}$ tergolong sangat rendah, Al-dd dan $\mathrm{H}$-dd masing-masing 4,8 dan $1,1 \mathrm{cmol}^{(+)} / \mathrm{kg}$ serta kejenuhan Al sangat tinggi $(65 \%)$. Rendahnya kesuburan Ultisol tersebut disebabkan oleh proses pelapukan yang sangat intensif akibat suhu dan curah hujan tinggi sehingga pencucian basa-basa intensif dan mineral liat dominan adalah liat silikat tipe 1:1 dan mineral sesquioksida yaitu $\mathrm{Al}$ oksida atau Al Hidroksida $\left\{\mathrm{Al}_{2} \mathrm{O}_{3} / \mathrm{Al}(\mathrm{OH})_{3}\right\}$ dan $\mathrm{Fe}$ oksida atau $\mathrm{Fe}$ hidroksida $\left\{\mathrm{Fe}_{2} \mathrm{O}_{3} / \mathrm{Fe}(\mathrm{OH})_{3}\right\}$ (Havlin et al., 1999). Ketiga tipe liat tersebut mempunyai KTK rendah terutama sequioksida KTKnya sangat rendah yaitu $0-3 \mathrm{cmol}^{(+) / / k g}$. Nilai $\mathrm{pH}$ tanah lebih kecil dari nilai pKA Al yaitu 5,5 menyebabkan oksida dan hidroksida Al larut sehingga kelarutan $\mathrm{Al}^{3+}$ dan kejenuhan $\mathrm{Al}$ tinggi.

\section{Tinggi Tanaman}

Tabel 1 menunjukkan bahwa pemberian FA dosis $30 \mathrm{~kg} \mathrm{P}_{2} \mathrm{O}_{5} /$ ha dicampur $10 \mathrm{t}$ cocpeat/ha atau tanpa cocopeat meningkat tinggi tanaman secara nyata dibandingkan tanpa FA, namun peningkatan dosis ke 45 dan $60 \quad \mathrm{P}_{2} \mathrm{O}_{5} /$ ha pengaruhnya tidaknyata baik pada kondisi kadar air KL maupun 25\% dibawah KL. Hal ini menunjukkan bahwa pemberian FA hingga dosis $30 \mathrm{~kg} \mathrm{P}_{2} \mathrm{O}_{5} /$ ha diperlukan untuk meningkatkan konsentrasi $\mathrm{P}$ tersedia di dalam tanah dan meningkatan serapan $\mathrm{P}$ oleh tanaman. 
Tabel 1. Pengaruh interaksi campuran FA dengan cocopeat dan kadar air terhadap tinggi tanaman padi gogo pada medium Ultisol

\begin{tabular}{cccccccc}
\hline \multirow{2}{*}{ Kadar Air } & \multicolumn{3}{c}{$\mathrm{FA}\left(\mathrm{kg} \mathrm{P}_{2} \mathrm{O}_{5} / \mathrm{ha}\right)+$ Cocopeat $(\mathrm{t} / \mathrm{ha})$} & \multicolumn{3}{c}{$\mathrm{FA}\left(\mathrm{kg} \mathrm{P}_{2} \mathrm{O}_{5} / \mathrm{ha}\right)$ tanpa Cocopeat } \\
\cline { 2 - 8 } & $0+10$ & $30+10$ & $45+10$ & $60+10$ & 30 & 45 & 60 \\
\hline \multirow{2}{*}{ KL } & $71,66 \mathrm{~d}$ & $81,33 \mathrm{abc}$ & $85,33 \mathrm{ab}$ & $87,00 \mathrm{a}$ & $80,66 \mathrm{abc}$ & $81,33 \mathrm{ab}$ & $82,33 \mathrm{abc}$ \\
$25 \%$ & $70,00 \mathrm{~d}$ & $80,00 \mathrm{bc}$ & $82,33 \mathrm{abc}$ & $86,00 \mathrm{ab}$ & $77,66 \mathrm{c}$ & $81,66 \mathrm{abc}$ & $81,33 \mathrm{ab}$ \\
\hline
\end{tabular}

Keterangan: Angka-angka pada kolom dan baris yang sama yang diikuti oleh huruf kecil yang sama berbeda tidak nyata menurut Uji DMRT pada taraf 5\%.

Di dalam tanaman $\mathrm{P}$ berperan dalam proses fisiologi dan metabolisme. Menurut Salisbury dan Ross (1995) hara P berperan penting dalam proses fotosintesis, respirasi, pembelahan dan pembesaran sel. Hara $\mathrm{P}$ diinkorporasi ke dalam bentuk ATP yaitu senyawa berenergi tinggi dan berperan dalam proses fisiologi seperti fotosintesis dan metabolisme tanaman. Peningkatan serapan $\mathrm{P}$ memacu proses fisiologi dan metabolisme tanaman sehingga fotosintat hasil fotosintesis dan berbagai senyawa organik hasil metabolisme meningkat dalam tanaman. Senyawa organik yang terbentuk diantaranya sebagai komponen penyusun sel tanaman sehingga meningkatkan pertumbuhan dalam hal ini tinggi tanaman. Hal yang sama di laporkan Zulputra et al. (2014) bahwa pemberian pupuk $\mathrm{P}$ (SP-36) dosis $36 \mathrm{~kg}$ $\mathrm{P}_{2} \mathrm{O}_{5} /$ ha pada ultisol Rokan Hulu Riau meningkatkan tinggi tanaman.

Jumlah anakan maksimum
Pemberian FA dosis $30 \mathrm{~kg} \mathrm{P}_{2} \mathrm{O}_{5} /$ ha dicampur cocopeat dosis $10 \mathrm{t} / \mathrm{ha}$ meningkatkan jumlah anakan maksimum lebih tinggi dari pada tanpa cocopeat dibandingkan tanapa FA baik pada kondisi KL maupun $25 \%$ dibawah KL, peningkatan tertinggi diperoleh pada kondisi KL dengan pemberian FA dosis $45 \mathrm{P}_{2} \mathrm{O}_{5} / \mathrm{ha}$ dicampur cocopeat $10 \mathrm{t} / \mathrm{ha}$ (Tabel 2). Serapan hara meningkat dengan meningkatnya kadar air tanah karena air berperan sebagai pelarut mineral/pupuk dan alat transportasi ion di dalam tanah maupun dalam tanaman Serapan hara juga meningkat karena volume akar terutama bulu akar/akar rambut akar karena $\mathrm{P}$ berperan dalam pertumbuhan dan perkembangan akar. Menurut Widawati dan Kanti (2000) P berperan dalam perkembangan akar khususnya akar lateral dan akar halus. Peningkatan volume akar diikuti peningkatan ketersediaan air dan hara akan meningkatkan jumlah air dan hara di serap tanaman, selanjutnya semakin memacu proses fisiologi dan metabolisme dalam tanaman.

Tabel 2. Pengaruh interaksi campuran FA dengan cocopeat dan kadar air terhadap jumlah anakan maksimum padi gogo pada medium Ultisol

\begin{tabular}{cccccccc}
\hline \multirow{2}{*}{ Kadar Air } & \multicolumn{3}{c}{$\mathrm{FA}\left(\mathrm{kg} \mathrm{P}_{2} \mathrm{O}_{5} / \mathrm{ha}\right)+$ Cocopeat $(\mathrm{t} / \mathrm{ha})$} & \multicolumn{3}{c}{$\mathrm{FA}\left(\mathrm{kg} \mathrm{P}_{2} \mathrm{O}_{5} / \mathrm{ha}\right)$ tanpa Cocopeat } \\
\cline { 2 - 7 } & $0+10$ & $30+10$ & $45+10$ & $60+10$ & 30 & 45 & 60 \\
\hline \multirow{2}{*}{ KL } & $24,66 \mathrm{~d}$ & $37,33 \mathrm{bc}$ & $47,33 \mathrm{a}$ & $48,00 \mathrm{a}$ & $31,66 \mathrm{c}$ & $37,66 \mathrm{bc}$ & $46,00 \mathrm{a}$ \\
25\% & $21,66 \mathrm{~d}$ & $34,66 \mathrm{c}$ & $43,00 \mathrm{ab}$ & $47,66 \mathrm{a}$ & $32,00 \mathrm{c}$ & $35,00 \mathrm{c}$ & $45,00 \mathrm{a}$ \\
dibawah KL & & & &
\end{tabular}

Keterangan: Angka-angka pada kolom dan baris yang sama yang diikuti oleh huruf kecil yang sama berbeda tidak nyata menurut Uji DMRT pada taraf 5\%. 
Air merupakan komponen utama pembetukan karbohidrat pada proses fotosintesis dan sumber ion $\mathrm{H}^{+}$dan $\mathrm{OH}^{-}$dalam proses metabolisme. Semakin besar produk hasil fotosintesis (fotosintat) dan metabolisme (senyawa organik) yang dihasilkan sebagai komponen penyusun sel maka semakin berkembang jaringan tanaman. Zulputra et al. (2014) melaporkan bahwa pemberian pupuk $\mathrm{P}$ dosis $36 \mathrm{~kg} \quad \mathrm{P}_{2} \mathrm{O}_{5} / \mathrm{ha}$ meningkatkan jumlah anakan maksimum namun peningkatan takaran 54 dan $72 \mathrm{~kg} \mathrm{P}_{2} \mathrm{O}_{5} /$ ha berpengaruh tidak nyata terhadap jumlah anakan maksimum padi pada ultisol Rokan Hulu Riau. Bustami et al (2012) melaporkan bahwa pemberian pupuk $\mathrm{P}$ dosis $50 \mathrm{~kg} \mathrm{P}_{2} \mathrm{O}_{5} /$ ha meningkatkan jumlah anakan dibandingkan tanpa pupuk $\mathrm{P}$.

\section{Jumlah anakan produktif}

Tabel 3 menunjukkan bahwa pemberian FA dosis $30 \mathrm{~kg} \mathrm{P}_{2} \mathrm{O}_{5} / \mathrm{ha}$ meningkat jumlah anakan produktif semakin tinggi dosis $(45-60 \mathrm{~kg}$ $\mathrm{P}_{2} \mathrm{O}_{5} /$ ha) jumlah anakan cenderung meningkat lebih tinggi baik dicampur cocopeat dosis $10 \mathrm{t} /$ ha atau tanpa cocopat dibandingkan tanpa FA pada kondisi kadar air KL dan 25\% dibawah KL. Jumlah anakan produktif paling tinggi 36,66 batang/rumpun diperoleh pada pemberian $60 \mathrm{~kg} \mathrm{P}_{2} \mathrm{O}_{5} / \mathrm{ha}$ dicampur cocopeat 10 t/ha kondisi air Kl. Jumlah tersebut 3 kali lebih besar dibandingkan deskripsi varietas Situ Bagendit menurut BBPTP (2015) yaitu sekitar 12-13 batang/rumpun. Peningkatan jumlah anakan prouktif yang pantastik ini sangat erat kaitannya dengan peningkatan ketersediaan $\mathrm{P}$ melalui pemberian FA dan ketersediaan air melalui pemberian air hingga KL dan pemberian cocopeat karena kemampuannya menyerap dan memegang air sangat tinggi. Pemberian cocopeat juga menekan fiksasi $\mathrm{P}$ oleh mineral tanah atau kation berpalensi dua atau lebih. Peranan cocopeat dalam meningkatkan ketersediaan air erat kaitannya dengan sidat fisik dan kimianya. Cocopeat mempunyai berat jenis $0,75 \mathrm{~g} / \mathrm{cm}^{3}$, berat volume $0,13 \mathrm{~g} / \mathrm{cm}^{3}$ dan porositas $91,9 \%$ (Agustin, 2010). Ghehsareh et al., (2011) melaporkan bahwa kharakteristik cocopeat sebagai berikut: nisbah $\mathrm{C} / \mathrm{N}$ 48, $\mathrm{BD} 0,16$ $\mathrm{g} / \mathrm{cm}, \mathrm{pH} 6,7$, KTK $138,7 \mathrm{Cmol}^{(+)} / \mathrm{kg}$ ), N-total $1,98 \mathrm{mg} / \mathrm{L}$, P Olsen $1,32 \mathrm{mg} / \mathrm{L}$ dan $\mathrm{K}$ olsen $477,7 \mathrm{mg} / \mathrm{L}$. serta porositas $58 \%$ dan water holding capasity (WHC) 90,5\% serta kadar air dan daya simpan air sangat tinggi masingmasing $119 \%$ dan $695,4 \%$.

Tabel 3. Pengruh interaksi campuran FA dengan cocopeat dan kadar air terhadap jumlah anakan maksimum produktif padi gogo pada medium Ultisol

\begin{tabular}{|c|c|c|c|c|c|c|c|}
\hline \multirow[b]{2}{*}{ Kadar Air } & \multicolumn{4}{|c|}{ FA $\left(\mathrm{kg} \mathrm{P}_{2} \mathrm{O}_{5} / \mathrm{ha}\right)+$ Cocopeat $(\mathrm{t} / \mathrm{ha})$} & \multicolumn{3}{|c|}{ FA $\left(\mathrm{kg} \mathrm{P}_{2} \mathrm{O}_{5} / \mathrm{ha}\right)$ tanpa Cocopeat } \\
\hline & $\begin{array}{l}0+ \\
10\end{array}$ & -10 & $5+10$ & $60+10$ & 30 & 45 & 60 \\
\hline & \multicolumn{7}{|c|}{ Jumlah Anakan Produktif (batang/rumpun) } \\
\hline KI & $20,00 \mathrm{ef}$ & $28,33 \mathrm{bcd}$ & 34,00 & $36,66 \mathrm{a}$ & $26,66 \mathrm{~d}$ & $29,33 \mathrm{bcd}$ & $34,00 \mathrm{abc}$ \\
\hline $\begin{array}{c}25 \% \\
\text { dibawah KL }\end{array}$ & $17,00 \mathrm{f}$ & $27,33 \mathrm{~cd}$ & 33,66 & $34,33 \mathrm{ab}$ & $25,33 \mathrm{de}$ & $27,66 \mathrm{bcd}$ & $33,66 a b c$ \\
\hline
\end{tabular}

Keterangan: Angka-angka pada kolom dan baris yang sama yang diikuti oleh huruf kecil yang sama berbeda tidak nyata menurut Uji DMRT pada taraf 5\%.

Sehubungan dengan kharakteristik cocopeat menyebabkan ketersediaan air dan hara terutama $\mathrm{P}$ dalam jumlah yang cukup untuk kebutuhan tanaman terjamin dari awal fase generatif pembentukan malai atau pembungaan hingga akhir fase generatif. Proses fisiologi dan metabolisme telah dipacu sejak awal fase vegetatif menyebabkan pertumbuhan akar dan tajuk tanaman meningkat dimana kondisi tersebut besar perannya terhadap pertumbuhan tanaman pada awal hingga akhir fase generatif yang dicerminkan oleh tingginya jumlah anakan produktif dan bobot jerami kering per rumpun (Tabel 3 dan 4).

Bobot Kering Jerami 
Tabel 4 menunjukkan bahwa pemberian FA dosis $30 \mathrm{~kg}$ dicampur cocopeat dosis $10 \mathrm{t} / \mathrm{ha}$ atau tidak dicampur meningkatkan bobot kering jerami dibandingkan tanpa FA, peningkatannya cenderung lebih tinggi dengan meningkatnya dosis ke 45-60 kg $\mathrm{P}_{2} \mathrm{O}_{5} /$ ha baik baik pada KL maupun 25\% dibawah KL. Bobot kering jerami tertinggi diperoleh pada pemberian FA dicampur cocopeat kondisi KL. Hal ini erat kaitannya dengan peningkatan pertumbuhan tanaman sejak awal fase vegetatif hingga fase generatif karena peningkatan ketersediaan hara khusus $\mathrm{P}$ dan air akibat perlakuan yang diberikan. Sebagaimana telah dijelaskan bahwa $\mathrm{P}$ berperan dalam proses fisiologi dan metabolisme tanaman. Bobot kering jerami adalah akumulasi/total biomasa tanaman yang ditentukan oleh tinggi tanaman, jumlah anakan maksimum dan produktif.

Tabel 4. Pengruh interaksi campuran FA dengan cocopeat dan kadar air terhadap bobot kering jerami padi gogo pada medium Ultisol

\begin{tabular}{cccccccc}
\hline \multirow{2}{*}{ Kadar Air } & \multicolumn{3}{c}{$\mathrm{FA}\left(\mathrm{kg} \mathrm{P}_{2} \mathrm{O}_{5} / \mathrm{ha}\right)+$ Cocopeat $(\mathrm{t} / \mathrm{ha})$} & \multicolumn{2}{c}{$\mathrm{FA}\left(\mathrm{kg}_{2} \mathrm{O}_{5} / \mathrm{ha}\right)$ tanpa Cocopeat } \\
\cline { 2 - 7 } & $0+10$ & $30+10$ & $45+10$ & $60+10$ & 30 & 45 & 60 \\
\hline \multirow{2}{*}{ KL } & 30,39 ef & $46,64 \mathrm{abcd}$ & $52,24 \mathrm{abc}$ & $55,69 \mathrm{a}$ & 44,11 abcd & 45,40 abcd & $49,68 \mathrm{abcd}$ \\
$25 \%$ & $27,86 \mathrm{f}$ & $40,38 \mathrm{de}$ & $51,62 \mathrm{abcd}$ & $52,95 \mathrm{ab}$ & $40,58 \mathrm{cde}$ & $41,36 \mathrm{bcd}$ & $49,02 \mathrm{abcd}$ \\
dibawa KL & & & & &
\end{tabular}

Keterangan: Angka-angka pada kolom dan baris yang sama yang diikuti oleh huruf kecil yang sama berbeda tidak nyata menurut Uji DMRT pada taraf 5\%.

Peran $\mathrm{P}$ dalam proses metabolisme sebagai sumber energi berupa senyawa ATP. Sebagai contoh ATP dibutuhkan pada proses glikolisis karbohidrat $\left(\mathrm{C}_{6} \mathrm{H}_{12} \mathrm{O}_{6}\right)$ dalam menghasilkan Acetyl CoA. Acetyl CoA selanjutnya dimetabolisme menjadi berbagai senyawa diantaranya asam amino dan ATP. Asam amino sebagai penyusun protein, dimana protein merupakan komponen inti sel. Pertumbuhan tanaman atau pembentukan jaringan diawali dari pembelahan sel. Pembelahan sel membutuhkan ATP dengan demikian peningkatan serapan $\mathrm{P}$ memacu pembelahan sel atau pertumbuhan tanaman. Lambers etal, (2008) menyatakan bahwa fosfor merupakan komponen penting penyusun senyawa untuk transfer energi (ATP dan nukleoprotein), yang berperan sebagai sumber energi pada proses metabolisme. Munawar (2011) menyatakan bahwa fosfor penting dalam reaksi fotosintesis tanaman, dari pertumbuhan tanaman muda sampai pembentukan bunga. De Datta (1981) menyatakan bahwa P diperlukan tanaman padi dalam perkembangan akar, mendorong pembentukan anakan, mempercepat pembungaan dan pematangan serta pembentukan biji. Hady (2013) melaporkan bahwa pemberian pupuk $\mathrm{P}$ dosis 1,28 ton SP36/ha meningkatkan Bobot kering jerami dibandingkan tanpa pupuk $\mathrm{P}$.

\section{KESIMPULAN}

Pemberian fosfat alam dosis $30 \mathrm{~kg}$ $\mathrm{P}_{2} \mathrm{O}_{5} /$ ha dicampur cocopeat dosis 10 ton/ha atau tidak dicampur meningkatkan pertumbuhan padi gogo yaitu tinggi tanaman, jumlah anakan maksimum, jumlah anakan produktif dan bobot kering jerami dibandingkan tanpa FA, baik pada kondisi kadar air KL maupun 25\% dibawah KL.

Tinggi ganaman, jumlah anakan maksimum dan produktif serta bobot kering jerami cenderung meningkat lebih tinggi dengan meningkatnya dosis ke 45-60 kg $\mathrm{P}_{2} \mathrm{O}_{5} /$ ha dicampur cocopeat dosis 10 t/ha atau tidak dicampur baik pada kondisi kadar air KL maupun $25 \%$ dibawah KL.

\section{DAFTAR PUSTAKA}

Ghehsareh, A.M., H. Borji and M. Jafarpour. 2011. Effect of some culture substrates 
(date-palm peat, cocopeat and perlite on some growing indices and nutrient elements uptake in greenhouse tomato. African Journal of Microbiology Research Vol. 5(12), pp. 1437-1442.

Agustin, L.F. 2010. Pemanfaatan Kompos Sabut Kelapa dan Zeolit Sebagai Campuran Tanah untuk Media Pertumbuhan Bibit Kakao pada Beberapa Tingkat Ketersediaan Air. Skripsi Fakultas Pertanian, Universitas Jember, Jember.

Balai Besar Penelitian Tanaman Padi. (BBPTP) 2015. Inbrida Padi Gogo. (Situ Bagendit). http://bbpadi.litbang.pertanian.go.id/index. php/varietas/inbrida padi gogo situ bagendit /content/item/60-situ bagendit. Diakses pada tanggal 17 Januari 2017

Bustami, Sufardi dan Bachtiar. 2012. Serapan Hara dan Efisiensi Pemupukan Phosfat serta Pertumbuhan Padi Varietas Lokal. Jurnal Manajemen Sumberdaya Lahan. Volume 1 (2). 159-170

De Datta, S.K. 1981. Fertilizer Management for Efficient Use in Wetland Rice Soil.In. Soil and Rice.IRRI, Los Banos, Philippines.

Hady, U. 2013. Pengaruh Trass dan Pupuk Fosfor terhadap Pertumbuhan dan Produksi Padi Gogo serta Perubahan Sifat Kimia pada Latosol Gunung Sindur.Skripsi Fakultas Pertanian, IPB. Bogor.

Hardjowigeno, S. 2007. Ilmu Tanah. Akademika Pressindo. Jakarta.

Hasriani, D. Kusnadi, dan A. Saputra. 2013. Kajian Serbuk Sabut Kelapa (Cocopeat) Sebagai Media Tanam. Departemen Teknik Sipil dan Lingkungan. Fakultas Teknologi Pertanian. IPB. Bogor.

Havlin, J.L., J.D. Beaton, S.L. Tisdale, and W.L. Nelson. 1999. Soil Fertility and
Fertilizers. An Introduction to Nutrient Management. Sicth Edition. Prentice Hall. Upper Saddle River, New Jersey.

Lambers, H., F.S. Chapin, and T.L. Pon. 2008. Plant Physiological Ecology. Springer

Lingga, P. dan Marsono. 2006. Petunjuk Penggunaan Pupuk. Penebar Swadaya. Jakarta.

Munawar, A. 2011. Kesuburan Tanah dan Nutrisi Tanah. IPB Press.Bogor

Prasetyo, B.H. dan D.A. Suriadikarta.2006, Karakteristik, potensi, dan teknologi pengelolaan tanah ultisol untuk pengembangan pertanian lahan kering di Indonesia.Jurnal Litbang Pertanian, volume 25 (2).39-46.

Salisbury, F.B dan C.W. Ross. 1995. Fisiologi Tumbuhan. Institut Teknologi Bandung.

Subagyo, H., N. Suharta, dan A.B. Siswanto. 2004. Tanah-tanah pertanian di Indonesia. hlm. 21-66.dalam A. Adimihardja, L.I. Amien, F. Agus, D. Djaenudin (Ed.). Sumberdaya Lahan Indonesia dan Pengelolaannya.Pusat Penelitian dan Pengembangan Tanah dan Agroklimat, Bogor.

Widawati S, S A. Kanti. 2000. Pengaruh Isolat Bakteri Pelarut Fosfat (BPF) Efektif dan Dosis Pupuk Fosfat terhadap Pertumbuhan Kacang Tanah (Arachis hypogaea). Lembaga Ilmu Pengetahuan Indonesia. Diakses http://elib.pdii.lipi.go.id/katalog/index.php /searchkatalog/do.

Zulputra, Wawan, Nelvia. 2014. Respon Padi Gogo terhadap Pemberian Silikat dan Pupuk Fosfat pada Tanah Ultisol. Jurnal Agroteknologi, Volume 4 (2). 1-10 